ARTICLE

\title{
Bimodal diel pattern in peatland ecosystem respiration rebuts uniform temperature response
}

\author{
Järvi Järveoja (i) ${ }^{1 凶}$, Mats B. Nilsson (10) ${ }^{1}$, Patrick M. Crill (i] ${ }^{2,3} \&$ Matthias Peichl (i) $^{1}$
}

Accurate projections of climate change impacts on the vast carbon stores of northern peatlands require detailed knowledge of ecosystem respiration (ER) and its heterotrophic (Rh) and autotrophic (Ra) components. Currently, however, standard flux measurement techniques, i.e. eddy covariance and manual chambers, generate empirical ER data during only night- or daytime, respectively, which are extrapolated to the daily scale based on the paradigm that assumes a uniform diel temperature response. Here, using continuous autochamber measurements, we demonstrate a distinct bimodal pattern in diel peatland ER which contrasts the unimodal pattern inherent to the classical assumption. This feature results from divergent temperature dependencies of day- and nighttime ER due to varying contributions from Rh and Ra. We further find that disregarding these bimodal dynamics causes significant bias in ER estimates across multiple temporal scales. This calls for improved process-based understanding of ER to advance our ability to simulate peatland carbon cycle-climate feedbacks.

\footnotetext{
${ }^{1}$ Department of Forest Ecology \& Management, Swedish University of Agricultural Sciences, Umeå, Sweden. ${ }^{2}$ Department of Geological Sciences, Stockholm University, Stockholm, Sweden. ${ }^{3}$ Bolin Centre for Climate Research, Stockholm, Sweden. ${ }^{凶}$ email: jarvi.jarveoja@slu.se
} 
$\mathrm{N}$ orthern peatlands have sequestered about $270-547 \mathrm{Gt}$ of carbon (C) since the end of the last glacial period, which represents $20-30 \%$ of the organic C currently stored in soils worldwide ${ }^{1-5}$. Ecosystem respiration (ER) is the dominant pathway for $\mathrm{C}$ losses from peatlands to the atmosphere, and recently concern has been raised that the loss rate might increase under future climate change ${ }^{6-9}$. Understanding the dynamics and controls of peatland ER is therefore imperative for making accurate predictions of climate change impacts on the peatland $\mathrm{C}$ sink-source strength.

Conceptually, ER is the sum of two fundamentally different processes, i.e., microbial heterotrophic and plant autotrophic respiration ( $\mathrm{Rh}$ and $\mathrm{Ra}$, respectively). The magnitudes of each of these are the result of multiple soil biogeochemical and plant physiological processes ${ }^{10-12}$. This implies that the individual contributions of $\mathrm{Rh}$ and $\mathrm{Ra}$ to ER vary over space and time depending on biotic (e.g., plant species composition, biomass pools, phenology) and abiotic (e.g., air and soil temperature, solar radiation, water availability) conditions ${ }^{10,13}$. To accurately interpret the observed patterns in ER an in-depth mechanistic understanding of the spatio-temporal dynamics of $\mathrm{Rh}$ and $\mathrm{Ra}$ is essential.

Our current knowledge on the patterns and controls of diel peatland ER and its underlying components is, however, limited in no small part due to methodological constraints in the standard measurement techniques. Specifically, eddy covariance (EC) and manual dark chamber measurements provide only semicontinuous empirical ER data either at high frequency but limited to the nighttime (when the net $\mathrm{CO}_{2}$ exchange equals ER due to the absence of photosynthesis) or at coarse (e.g., weekly to biweekly) intervals and predominantly during only the daytime, respectively. Based on the well-established temperature dependency of respiration ${ }^{14-16}$, these periodic measurements are then extrapolated to the daily scale (and further to annual budgets) assuming a uniform diel temperature response ${ }^{17,18}$. However, given the additional underlying drivers and their diel variations, these simple temperature response functions are prone to fail in accurately simulating ER over the entire diel cycle ${ }^{19,20}$.

As an alternative, an automated dark chamber system provides direct ER estimates (in short-canopy ecosystems) at high temporal resolution (e.g., hourly) throughout the full diel cycle. While such systems have previously been used to measure diel respiration fluxes in forests ${ }^{21-23}$, grasslands ${ }^{20,24}$ and croplands $^{25}$, similar studies are lacking in northern peatland ecosystems. As a result, our current knowledge of peatland ER dynamics and budgets relies heavily on the conceptual assumptions inherent to the models used for extrapolating semi-continuous diel data to daily and annual scales.

Here, we use an autochamber (AC) system installed across experimental plots ${ }^{13}$ to capture the complete diel cycles of ER and its underlying components (i.e., $\mathrm{Rh}$ and $\mathrm{Ra}$ ) at an hourly resolution in a boreal minerogenous peatland over 3 years. To further investigate their separate abiotic and biotic controls, we explore the coherence of these diel fluxes with comprehensive environmental and vegetation data. Next, we compare our diel AC ER estimates with those obtained from extrapolating the nighttime AC data to the daytime to test a standard ER modeling approach $^{26}$ widely used within the flux community (see Methods). We observe a distinct bimodal pattern in ER and a divergence in its response to temperature throughout the diel cycle, which emanates from the contrasting dynamics of $\mathrm{Rh}$ and $\mathrm{Ra}$. These findings highlight the need for recognizing ER as a composite flux and for moving towards a detailed process-based understanding of its individual $\mathrm{Rh}$ and $\mathrm{Ra}$ components in northern peatlands.

\section{Results}

Bimodal diel pattern in peatland ER. Our continuous AC ER measurements revealed that ER peaked at both midday as well as around midnight from green-up to senescence (see $E_{A C}$ in Fig. 1a-c; Supplementary Fig. 1a-c). It is further noteworthy that the secondary nighttime maximum was of similar magnitude to the daytime one during the green-up and senescence phases. Meanwhile, maximum daytime ER was about 25\% higher compared to the nighttime during the peak season. These observed bimodal diel ER patterns diverge from the unimodal ER dynamics obtained from extrapolating our nighttime AC ER data with the standard flux modeling approach ${ }^{26}$ (see $E_{M}$ in Fig. 1a-c). Similarly, the diel AC ER patterns contrast the unimodal diel ER estimates derived from adjacent (i.e., $\sim 25 \mathrm{~m}$ ) EC measurements which rely on the same modeling procedure (Supplementary Fig. 2a-c), i.e., extrapolating nighttime ER to the daytime assuming a uniform diel temperature response. Furthermore, while our AC data agree with the standard approach on a unimodal diel ER pattern during dormancy, they suggest a daytime minimum and nighttime maximum (Fig. 1d; Supplementary Fig. 1d) which is de facto reverse to the diel ER patterns of the model extrapolation (Fig. 1d) and EC-based estimates (Supplementary Fig. 2d).
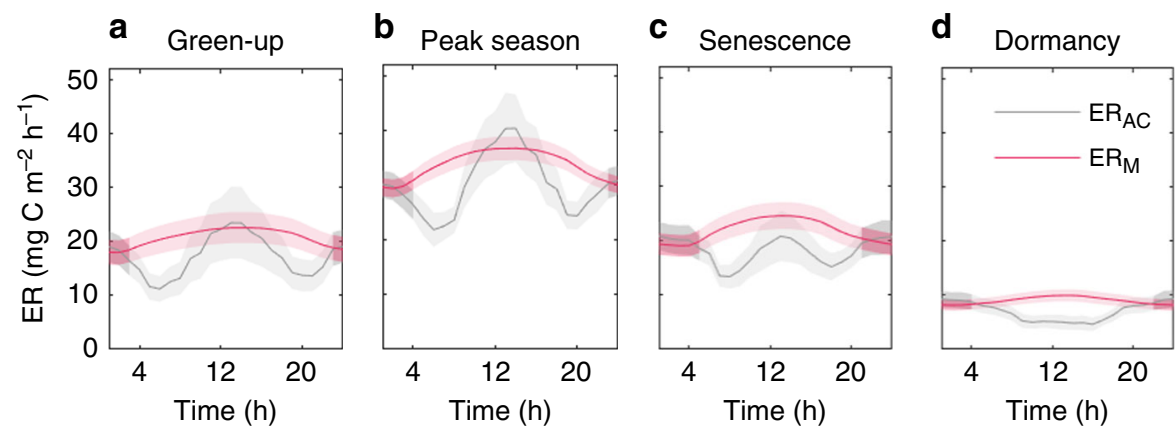

Fig. 1 Diel patterns of measured versus extrapolated ecosystem respiration. Diel patterns of ecosystem respiration (ER) measured by autochambers $\left(E R_{A C}\right)$ and estimated by a standard flux modeling approach that extrapolated nighttime $E R_{A C}$ data to the daytime (ER $\left.R_{M}\right)$ during the key phenophases of a green-up, b peak season, c senescence and d dormancy (spring and autumn) shown as a mean of the years 2015-2017 (see Supplementary Fig. 1 for $\mathrm{ER}_{\mathrm{AC}}$ results from individual years). Shaded bands indicate \pm 1 standard error for a given hour resulting from the variation within each phenophase and across the 3 years. Darker shading shows the nighttime hours of the diel cycle. $\mathrm{ER}_{\mathrm{M}}$ is modeled based on an exponential relationship between nighttime $\mathrm{ER}_{\mathrm{AC}}$ and air temperature using the REddyProcWeb online gap-filling tool (Wutzler et al. ${ }^{26}$; see Methods for details). 
The divergence in the hourly measured and modeled (i.e., extrapolated) ER estimates was largest during the day-night transition periods (compare $\mathrm{ER}_{\mathrm{AC}}$ and $\mathrm{ER}_{\mathrm{M}}$ in Fig. 1). Over the course of the snow-free season, the ratio of the hourly modeled and measured ER estimates ranged from about 0.5 to $>5$ (Supplementary Fig. 3). We further find a consistent positive bias in daily ER estimates derived from the extrapolation of nighttime AC data (with up to two times higher values during the spring dormancy and green-up phases) compared to our measured daily ER (Fig. 2). Aggregating this daily bias resulted in an overestimation of cumulative ER over the snow-free season by 16,17 , and $22 \%$ in 2015,2016 , and 2017 , respectively (see Supplementary Fig. 4). Conversely, we estimate that extrapolating daytime ER data from manual chamber measurements based on a uniform diel response to temperature would underestimate ER over the snow-free season on average by $17 \%$ (Supplementary Table 1).

In contrast to the uniform diel relationship between ER and air temperature $(\mathrm{Ta})$ assumed by the standard approach to extrapolate semi-continuous ER measurements, the response of our measured AC ER to changes in Ta varied between day- and nighttime (Fig. 3). Specifically, the parameter representing base

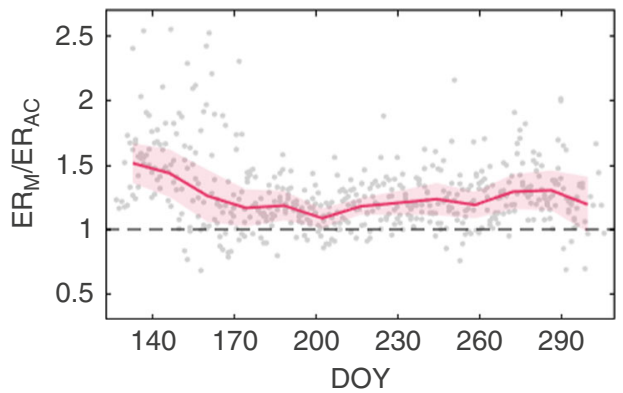

Fig. 2 Daily bias in extrapolated ecosystem respiration estimates. Ratios of daily ecosystem respiration (ER) estimated by a standard flux modeling approach $\left(E R_{M}\right)$ and measured by autochambers $\left(E R_{A C}\right)$. Symbols indicate ratios of daily $E R_{M}$ and $E R_{A C}$ for the years 2015-2017; the red line represents the block-average (window size $=14$ days) with shaded bands indicating \pm 1 standard error. Horizontal dashed line represents unity of the ratio. The 3-year means of the phenophase transition dates (DOY day of year) are as follows: 143 (spring dormancy $\rightarrow$ green-up), 187 (green-up $\rightarrow$ peak season), 218 (peak season $\rightarrow$ senescence), and 272 (senescence $\rightarrow$ autumn dormancy). respiration rates at $10^{\circ} \mathrm{C}\left(R_{10}\right)$ in the Lloyd \& Taylor respiration model $^{14}$ (see equation in Methods) was consistently about two times higher during nighttime compared to daytime in each phenophase. Meanwhile, the model parameter describing the sensitivity of respiration to a change in temperature $\left(E_{0}\right)$ was always significantly higher during the daytime. The magnitudes of the deviations between day- and nighttime parameters, however, varied throughout the different phenophases (Fig. 3) as well as among the individual years (Supplementary Fig. 5).

Diel patterns and controls of Rh and Ra. To help explain the observed diel patterns and temperature dependency of ER, we investigated the underlying $\mathrm{Rh}$ and $\mathrm{Ra}$ fluxes as well as their controls using an in situ flux partitioning approach with natural and experimental trenching/vegetation removal plots.

We found that $\mathrm{Rh}$ fluxes were generally lower during the daytime and reached a maximum during the midnight hours in all growth phases (Fig. 4a-c; Supplementary Fig. 6a-c). During the peak season, an additional increase in Rh occurred around noon (Fig. 4b; Supplementary Fig. 6b). In contrast, during dormancy Rh followed a weak diel pattern with somewhat higher fluxes occurring during the night (Fig. 4d; Supplementary Fig. 6d). A wavelet coherence analysis revealed that the observed diel patterns of Rh followed most closely those of soil temperature (Ts) (Fig. 5a-c; Supplementary Fig. 7a-c) while being anticyclical to those of $\mathrm{Ta}$ (Supplementary Fig. 8a, b) and only weakly coherent with those of water table level (WTL) (Supplementary Fig. $8 c$, d) throughout the various phenophases. However, the intermittent daytime increase in $\mathrm{Rh}$ observed during the peak season phase coincided with the daytime maxima in Ta (Fig. 4b). Across the measured levels, Ts at the $18 \mathrm{~cm}$ depth was most closely in sync with Rh while forward and backward lags of several hours were observed for temperature at higher (i.e., $10 \mathrm{~cm}$ ) and lower (i.e., $26 \mathrm{~cm}$ ) depths, respectively. Meanwhile, Welch's cross power spectral density values were highest for Ts at the $10 \mathrm{~cm}$ depth in each phenophase (Fig. 5a-c; Supplementary Figs. $7 a-c, 9 a-d)$. Overall, the correlations with temperature at single given depths remained, however, relatively weak. When further separating the phenophases into dry and wet conditions, we found that during the peak season both day- and nighttime $\mathrm{Rh}$ fluxes were higher (with similar relative increases) under dry conditions (Supplementary Fig. 10b). In comparison, WTL effects on the diel Rh patterns were limited during the other phenophases (Supplementary Fig. 10a, c, d).
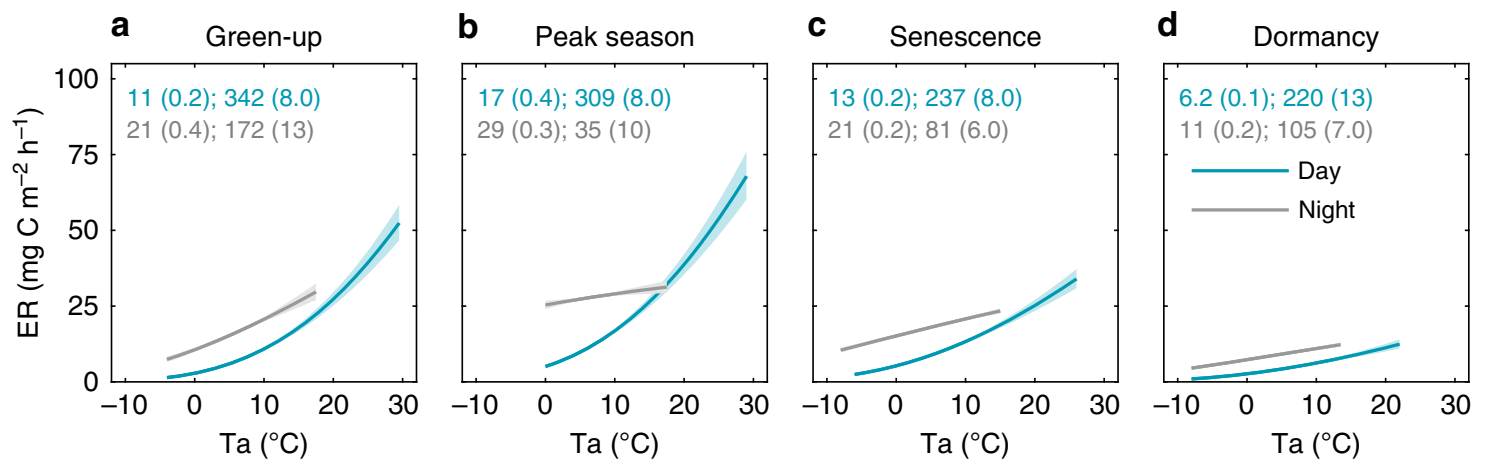

Fig. 3 Diel divergence in the temperature response of ecosystem respiration. Exponential regression relationships between ecosystem respiration (ER) measured by autochambers and air temperature ( $\mathrm{Ta}$ ) for day- and nighttime (i.e., photosynthetic photon flux density $\geq 20$ and $<20 \mu \mathrm{mols} \mathrm{m}^{-2} \mathrm{~s}^{-1}$, respectively) during the key phenophases of $\mathbf{a}$ green-up, $\mathbf{b}$ peak season, $\mathbf{c}$ senescence and $\mathbf{d}$ dormancy (spring and autumn) shown as a mean of the years 2015-2017 (see Supplementary Fig. 5 for results from individual years). Values shown in the panels (blue and gray for day-and nighttime periods,

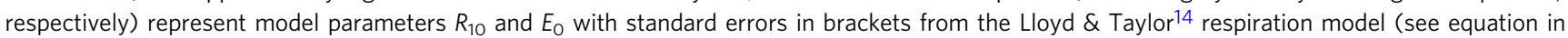
Methods). Solid lines indicate the exponential fit and shaded bands indicate the $95 \%$ confidence intervals. 

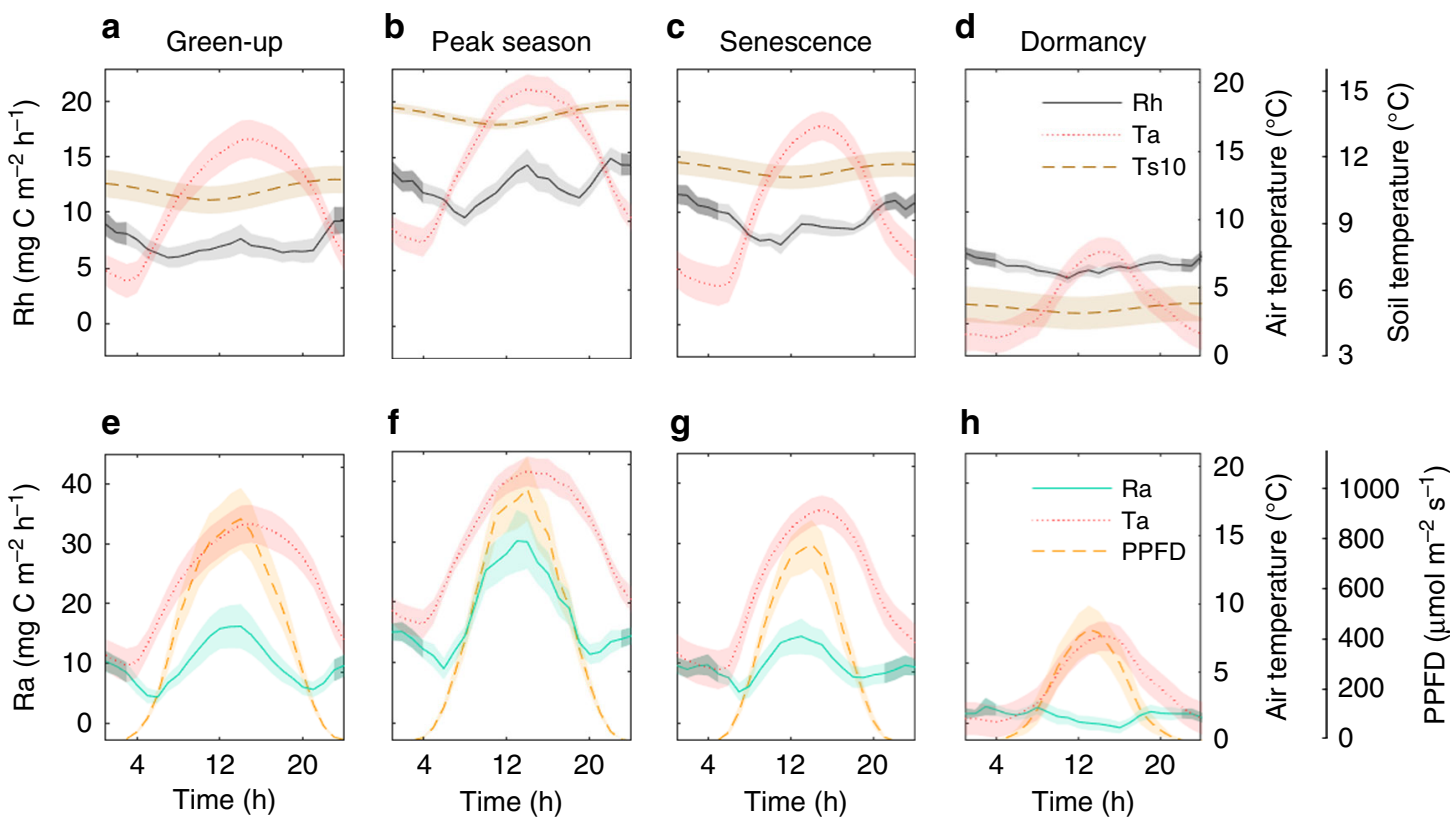

Fig. 4 Diel patterns of heterotrophic and autotrophic respiration. Diel patterns of $\mathbf{a}-\mathbf{d}$ heterotrophic respiration (Rh) and $\mathbf{e}-\mathbf{h}$ autotrophic respiration (Ra) and their main abiotic controls including air temperature ( $\mathrm{Ta}$ ), soil temperature at $10 \mathrm{~cm}$ depth (Ts10) and photosynthetic photon flux density (PPFD) during the phenophases of green-up, peak season, senescence, and dormancy (spring and autumn) shown as the mean over the years 2015-2016 (see Supplementary Fig. 6 for results from individual years; no Rh and Ra data were available in 2017). Shaded bands indicate \pm 1 standard error for a given hour resulting from the variation within each phenophase and across the measurement years. Darker shading in Rh and Ra shows the nighttime hours of the diel cycle.

The diel variations of plant-associated respiration, i.e., Ra, featured a similar though somewhat less pronounced bimodal pattern as ER. Specifically, maximum Ra occurred around noon during the green-up, peak season, and senescence phases (Fig. 4e-g; Supplementary Fig. 6a-c) exceeding that of $\mathrm{Rh}$ by about twofold. An additional relatively smaller peak was evident during the midnight hours reaching similar magnitudes as the concurrent $\mathrm{Rh}$ fluxes. As to be expected, no clear diel pattern occurred in $\mathrm{Ra}$ during dormancy (Fig. 4h). Results from the wavelet coherence analysis suggest that from green-up to senescence the diel patterns of Ra during daytime were regulated primarily by the temporal dynamics of the photosynthetic photon flux density (PPFD) and Ta (Fig. 5d-f; Supplementary Fig. 7d-f). In particular, the timing for the onset of the morning increase in $\mathrm{Ra}$ followed shortly that of Ta and PPFD while the onset of the afternoon decrease in $\mathrm{Ra}$ coincided with that of PPFD which showed an earlier and steeper decline compared to Ta (Fig. 4e-h). An assessment of the Welch's cross power spectral density confirmed that PPFD was overall a stronger control than $\mathrm{Ta}$ of the diel $\mathrm{Ra}$ pattern in each of the phenophases (Fig. 5d-f; Supplementary Fig. 9e-h). We further found that dry conditions in the peak season and senescence phases coincided with enhanced $\mathrm{Ra}$, with relatively larger increases during daycompared to nighttime (Supplementary Fig. 10b, c). Averaged over the snow-free season, the spatial variation in the diel amplitude of $\mathrm{Ra}$ exceeded that of $\mathrm{Rh}$ with daytime maximum $\mathrm{Ra}$ generally corresponding to differences in total green biomass across the four replicate chamber groups (Supplementary Fig. 11).

Our flux partitioning approach further revealed considerable differences in the temperature response between $\mathrm{Rh}$ and $\mathrm{Ra}$ as well as across diel and seasonal scales (Fig. 6), which altogether explain the observed variability in the temperature dependency of ER (Fig. 3). It is noteworthy that the day-nighttime hysteresis observed in the response of Rh to Ta (Fig. 6a-d) is largely reduced (except during senescence) when using Ts as the temperature driver (see Supplementary Fig. 12a-h). Further modifications of the temperature relationships were noted particularly for $\mathrm{Ra}$ and to a lesser extent for Rh during dry and wet periods (i.e., periods with a WTL below or above its respective phenophase mean) as a function of WTL fluctuations (for details see Supplementary Fig. 12).

\section{Discussion}

Our empirical evidence for bimodal diel ER patterns strongly contrasts with the established narrative of diel ER having a unimodal pattern emerging from the assumption of a uniform temperature response $17,26,27$. Our results further show that not considering the bimodal response may result in a significant bias in peatland ER estimates from hourly to annual scales. The implications from these findings are potentially far-reaching since this classical assumption is the foundation based on which many field studies extrapolate semi-continuous empirical ER data from $\mathrm{EC}^{17,26}$ and manual dark chamber ${ }^{28,29}$ measurements to the daily scale.

In particular, the manifold bias observed at hourly and daily scales significantly limits our process-based understanding of the ER response to external perturbations occurring at these shorter timescales (e.g., rainfall events, heat waves, and other weather patterns). The accumulated bias in ER over the snow-free season (ranging from 15 to $17 \mathrm{~g} \mathrm{C} \mathrm{m}^{-2}$ during the 3 measurement years) is also considerable since it represents about one quarter of the long-term mean annual net $\mathrm{CO}_{2}$ sink (NEE; $\left.58 \pm 21 \mathrm{~g} \mathrm{C} \mathrm{m}^{-2}\right)^{30}$ and about two-thirds of the annual net ecosystem carbon balance (NECB; $\left.23.5 \mathrm{~g} \mathrm{C} \mathrm{m}^{-2}\right)^{31}$. In addition, we estimated that using the manual chamber approach in which daytime relationships between ER and Ta are extrapolated to the nighttime would overestimate the cumulative net $\mathrm{CO}_{2}$ uptake during the snow-free 

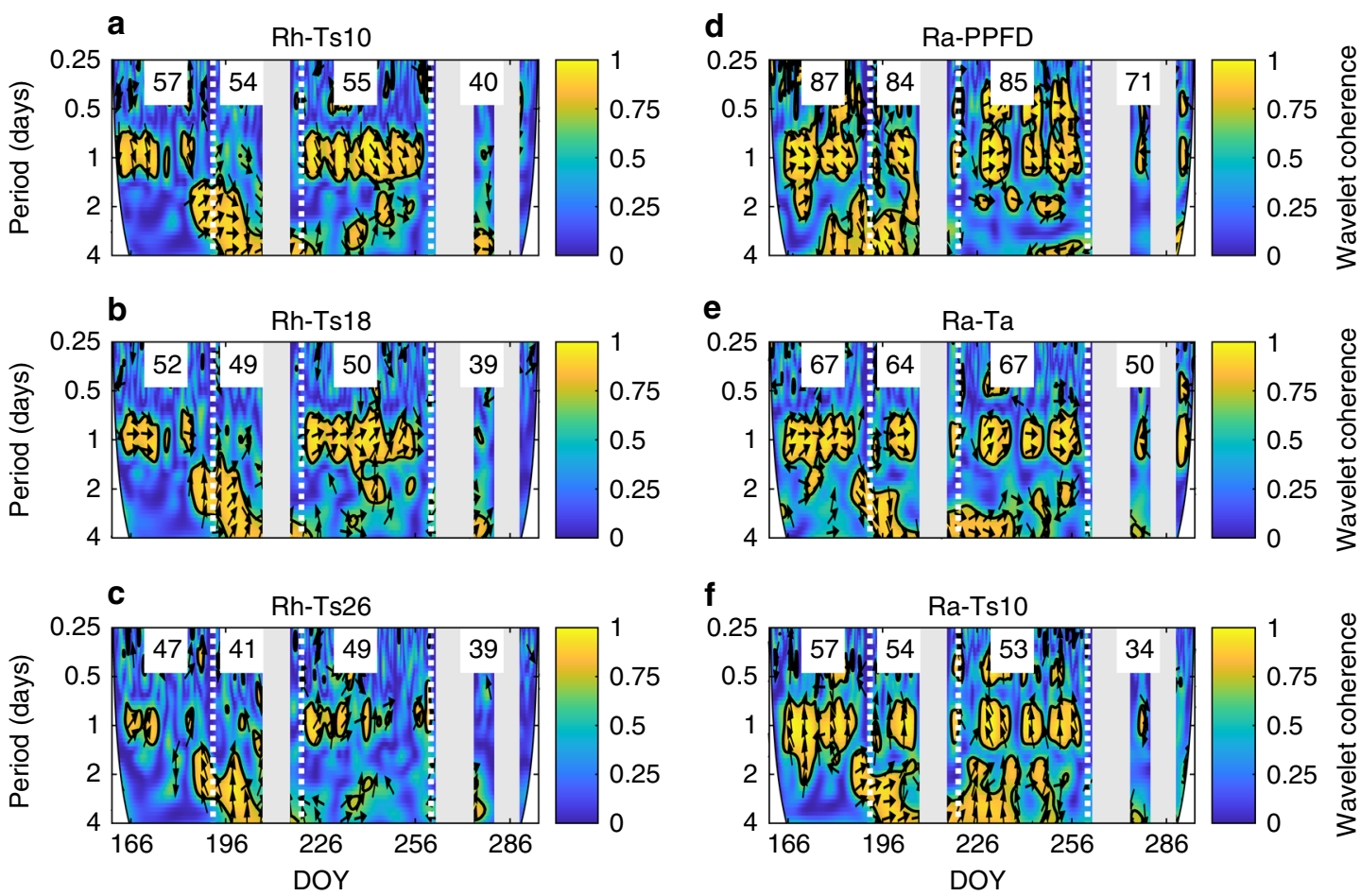

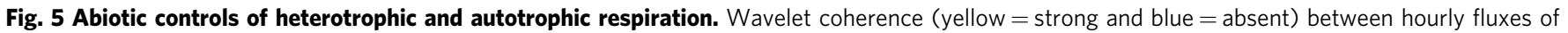
a-c heterotrophic respiration (Rh) and $\mathbf{d}-\mathbf{f}$ autotrophic respiration (Ra) and their abiotic controls (i.e., soil temperature at 10,18 , and $26 \mathrm{~cm}$ depth ( $\mathrm{Ts} 10$, Ts18, and Ts26), photosynthetic photon flux density (PPFD) and air temperature (Ta)) in 2015 (see similar results for 2016 in Supplementary Fig. 7 ; no Rh and Ra data were available in 2017). Arrows indicate lag: right = no lag, up or down = quarter diel cycle (i.e., $6 \mathrm{~h}$ ) lag of the flux behind or ahead of environmental variable, respectively, left = antiphase lag (i.e., $12 \mathrm{~h}$ ). Gray vertical bands indicate extended periods with missing hourly Rh and Ra data. Vertical dotted lines indicate transitions between the phenophases (green-up $\rightarrow$ peak season $\rightarrow$ senescence $\rightarrow$ autumn dormancy). Numbers in white boxes represent the Welch's cross power spectral density values between the hourly flux and environmental variables at the 1-day period (see also Supplementary Fig. 9). DOY stands for day of year.

season by $19 \%$ at our peatland site (see Supplementary Table 1 for more details). In comparison, such bias in ER does not affect the direct net $\mathrm{CO}_{2}$ exchange estimates by the EC technique. However, many process-based peatland models ${ }^{32-34}$ and remote sensing proxies $^{35-37}$ are developed (i.e., calibrated and validated) with the support of EC-derived ER estimates. Consequently, any bias in these observational data may not only hamper our understanding of processes at (sub-)daily timescales but also directly transfer into modeling estimates of regional and global peatland $\mathrm{C}$ budgets $^{38,39}$.

We show that the observed bias emanates from the failed assumption of a uniform relationship between ER and temperature ${ }^{17,29}$ for both day- and nighttime conditions. Supported by previous studies reporting a diel hysteresis between respiration and temperature in forest ${ }^{21,22}$ and grassland ${ }^{20,24}$ systems, our study demonstrates a divergence in both parameters of the exponential model describing ER response to air temperature between night- and daytime. In addition, we show that the magnitude of this divergence varies throughout the different phenophases. This highlights that despite the intrinsic temperature dependency of individual plant and microbial respiration processes, the whole system response is determined by their integrated sensitivity to the different temperature regimes aboveground and at various depths belowground. Combined with the effects from additional abiotic (e.g., radiation and water availability) and other biotic (e.g., phenology) drivers, this will in sum create diel ER patterns which contrast those expected from a uniform diel response to a single temperature parameter. Thus, our findings indicate a need for redefining our conceptual assumptions regarding diel ER dynamics in empirical and process-based modeling studies of the northern peatland $\mathrm{C}$ cycle.

Our experimental flux partitioning approach further revealed that the bimodal ER pattern resulted from the separate diel dynamics of $\mathrm{Ra}$ and $\mathrm{Rh}$ that reached their respective maxima at midday and midnight. Given the well-established temperature dependency of respiration ${ }^{14-16}$, diel $\mathrm{Rh}$ minima and maxima occurring during warmer day- and colder nighttime conditions, respectively, might at first appear counterintuitive. However, this phenomenon is resolved by the observed dependency of Rh to soil rather than air temperature with the former displaying a temporal shift in the diel maxima and minima with depth toward midnight and noon hours, respectively. Similarly, increases in soil respiration during the evening hours have also been previously noted in forest and cropland ecosystems ${ }^{21,23,25}$. It is noteworthy that the identified specific peat depth with highest coherence between its diel temperature dynamics and bulk Rh flux (i.e., the surface efflux) might not necessarily be the location of highest decomposition rates. Instead, it might merely represent the layer whose diel temperature pattern coincides best with the mean of the various diel decomposition dynamics occurring in the profile layers above and below. The observation that the most coherent peat depth was located below the mean WTL further demonstrates that relatively lower decomposition rates in the inundated anaerobic peat layers still contribute considerably to total $\mathrm{Rh}$ as they integrate over substantial depths (i.e., $>1 \mathrm{~m})^{40-45}$. The combined contribution from the various layers to the bulk $\mathrm{Rh}$ flux measured at the soil surface also explains its relatively weak correlations to temperature at a single peat depth. Thus, our results highlight that the diel variation in the bulk $\mathrm{Rh}$ flux is 

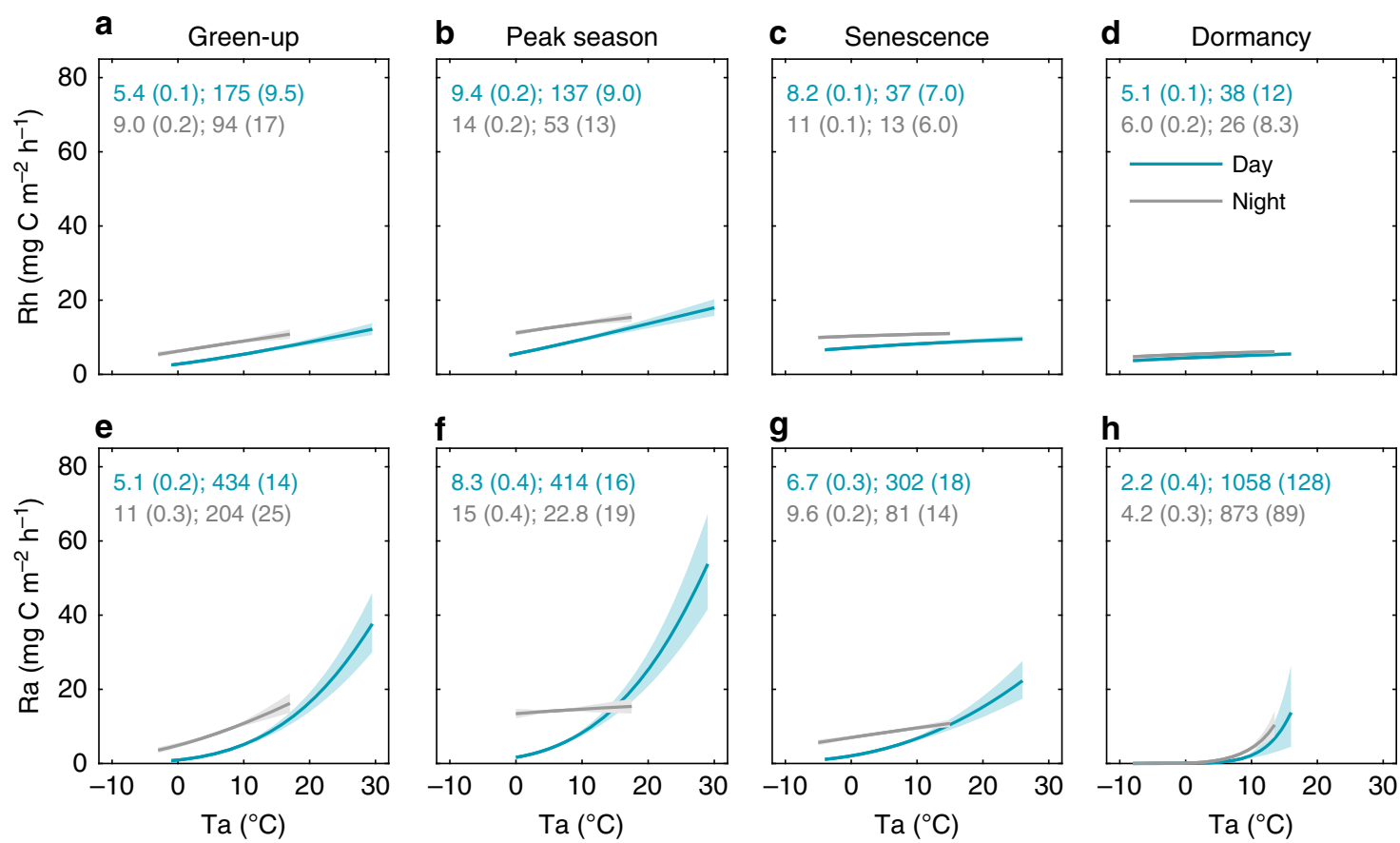

Fig. 6 Diel temperature responses of heterotrophic and autotrophic respiration. Exponential regression relationships between a-d heterotrophic respiration $(\mathrm{Rh})$ and $\mathbf{e}-\mathbf{h}$ autotrophic respiration $(\mathrm{Ra})$ and air temperature $(\mathrm{Ta})$ for day- and nighttime (i.e., photosynthetic photon flux density $\geq 20$ and $<20 \mu \mathrm{mols} \mathrm{m}^{-2} \mathrm{~s}^{-1}$, respectively) during the key phenophases of green-up, peak season, senescence, and dormancy (spring and autumn) shown as a mean of the years 2015-2016. Values shown in the panels (blue and gray for day- and nighttime periods, respectively) represent model parameters $R_{10}$ and $E_{0}$ with standard errors in brackets from the Lloyd \& Taylor ${ }^{14}$ respiration model (see equation in Methods). Solid lines indicate the exponential fit and shaded bands indicate the $95 \%$ confidence intervals.

regulated by a complex integral of depth-specific temperature dynamics with further modifications from water availability and substrate characteristics across the entire peat profile ${ }^{42,46,47}$. Compared to other terrestrial ecosystems (in particular tall canopy systems such as forests), peatlands are characterized by a relatively larger soil organic matter pool (i.e., up to several meters of peat) that sustains $\mathrm{Rh}$ and a smaller vegetation biomass pool, which limits the magnitudes of Ra. Thus, an enhanced contribution from diel $\mathrm{Rh}$ dynamics (relative to other ecosystem types) may facilitate a bimodal diel ER pattern as a unique feature for northern peatland ecosystems.

Meanwhile, the observed bimodal diel pattern in Ra may be explained by the individual dynamics in above- and belowground plant (i.e., rhizosphere) respiration processes in response to contrasting drivers. In particular, our results show that the pattern and magnitude of daytime Ra were strongly regulated by incoming solar radiation, air temperature, and water availability which are known drivers of vascular plant and moss photosynthesis ${ }^{48}$. In contrast, the secondary increase in Ra during nighttime might be due to elevated peat temperature and subsequently root respiration in combination with a lag in belowground allocation of recent photosynthates $21,49,50$ resulting in enhanced belowground Ra. However, the length of such lags in non-treed ecosystems has been reported to be highly variable ranging from hours to days depending on vegetation and soil hydrological characteristics ${ }^{25,50}$. Thus, the diel Ra (and subsequently ER) patterns might strongly depend on the site-specific timing of this allocation lag. The observed variations in maximum day- and nighttime $\mathrm{Ra}$ throughout the different phenophases (Fig. 4e-h) and in dependence of plant biomass (Supplementary Fig. 11b) further illustrate the important role of plant phenology (i.e., seasonal changes in biomass pools, photosynthetic capacity, and partitioning of above- to belowground production) in regulating $\mathrm{Ra}$ at seasonal and spatial scales. Overall, its greater variability and sensitivity to radiation (i.e., cloudiness), vegetation characteristics (Supplementary Fig. 11), and WTL (Supplementary Figs. 10 and 12) imply that Ra rather than $\mathrm{Rh}$ is the dominating component regulating the variations in the diel patterns and temperature response of ER.

Altogether, our results highlight that shifts in abiotic and biotic drivers due to climatic changes (including temperature, water balance, and cloudiness-dependent radiation regimes) might have contrasting effects on peatland ER depending on the individual responses of $\mathrm{Rh}$ and $\mathrm{Ra}$. However, more evidence is needed to identify how general these findings on the diel respiration fluxes are across peatland ecosystems, the biophysical factors that regulate it, and the implications for estimating ER from sub-daily to annual scales. This further calls for incorporating automated chamber measurements of diel ER and its component fluxes as a new standard in international C flux monitoring networks (e.g., ICOS, NEON).

\section{Methods}

Study site. The study was carried out at Degerö Stormyr $\left(64^{\circ} 11^{\prime} \mathrm{N} ; 19^{\circ} 33^{\prime} \mathrm{E}\right)$, which is an oligotrophic minerogenous mire (i.e., a nutrient-poor fen) in northern Sweden (Västerbotten County). The site is situated within the boreal region with a climate that can be classified as cold temperate humid. Previous studies at the site suggest a long-term (2001-2012) mean annual air temperature of $2.3^{\circ} \mathrm{C}$ and total annual precipitation of $666 \mathrm{~mm}^{30}$. The snow-free season lasts for about 6 months from around early May to late October. The WTL relative to the mire surface within our measurement area ranges between $\sim 0$ and $-15 \mathrm{~cm}$ with a snow-free season mean of $-4.7 \mathrm{~cm}^{13}$. The vegetation cover at the site consists of both Sphagnum spp. mosses as well as vascular plants. Specifically, the dominant species in the moss layer are $S$. majus Russ. C. Jens., S. lindbergii Schimp. and S. balticum Russ. C. Jens. The most typical vascular plant species include the sedges Eriophorum vaginatum L., Trichophorum cespitosum L. Hartm. and Scheuzeria palustris L. as well as the shrubs Vaccinium oxycoccos L. and Andromeda polifolia $\mathrm{L}^{31,51}$. 
Automated chamber system and experimental design. A custom-made automated chamber system (based on the design by Goulden \& Crill ${ }^{52}$; Bubier et al. ${ }^{53}$ ) was installed at the site during spring 2014 in close vicinity of the EC flux tower ${ }^{30}$. A detailed description of the experimental design and the technical specifications of the chamber system are presented by Järveoja et al. ${ }^{13}$. In brief, the set-up includes four replicate groups, each consisting of three adjacently placed chambers $(45 \times$ $45 \times 15 \mathrm{~cm}$ ): one transparent chamber for measuring the net ecosystem exchange of carbon dioxide (NEE) and two dark chambers for measuring ER and heterotrophic respiration (Rh). In this study, we present the ER data collected during the years 2015-2017. Due to frequent flooding of the vegetation removal (i.e., Rh) plots during the wet year 2017, detailed flux partitioning data for autotrophic respiration (Ra) and Rh was available only in 2015 and 2016.

The ER chambers are located within the natural (i.e., undisturbed) lawn microforms of the peatland. Meanwhile, the Rh chambers are established on experimental plots $\left(1 \mathrm{~m}^{2}\right)$ where all photosynthetic biomass (i.e., vascular plants and the upper $\sim 5 \mathrm{~cm}$ of the moss layer) was removed in autumn 2013. These plots were covered with artificial air and water permeable grass mats to maintain a similar surface albedo. In addition, the plot edges were trenched (to $\sim 40 \mathrm{~cm}$ depth) and new sporadically emerging shoots were clipped. A comparison of $\mathrm{Rh}$ fluxes during 2014-2016 suggests that the initial clipping in 2013 had no noticeable effect on $\mathrm{Rh}$ in the subsequent years. It is, however, important to note that such trenching/vegetation removal treatments can generally not separate Ra from the fraction of $\mathrm{Rh}$ that is associated with the microbial metabolism of fresh root exudates (i.e., originating from the belowground allocation of plant photosynthates $)^{54}$. Our flux partitioning approach thus somewhat underestimates the contribution from microbial respiration of these recently assimilated labile $\mathrm{C}$ sources while subsequently overestimating the relative contribution of Ra to ER. We expect, however, that this shortcoming has a limited impact on our results since this method-induced bias remains fairly constant and thus is unlikely to alter the diel patterns of $\mathrm{Ra}$ and $\mathrm{Rh}$.

Each chamber structure consists of a rectangular aluminum frame and a moving chamber. All chambers are made of transparent Lexan polycarbonate, however, the ER and Rh chambers were made dark using reflective aluminum tape. The frame includes a $10 \mathrm{~cm}$ deep skirt mounted at the bottom and a water groove on the top to ensure an airtight seal during the sampling. The chambers are connected in a closed loop to a cavity ringdown greenhouse gas analyzer (Model GGA-24EP, Los Gatos Research Inc., San Jose, CA, USA).

One chamber measurement cycle consists of three consecutive steps: (1) $1 \mathrm{~min}$ flushing of the sample tubing with ambient air while the chamber is still open, (2) followed by $3 \mathrm{~min}$ of concentration measurements during which the chamber is closed, and (3) concluded by another 1 min flushing of the sampling tubing once the chamber is open again. This results in a total measurement cycle of $5 \mathrm{~min}$ per chamber and consequently one measurement per hour from each of the 12 chambers. The measurement sequence is kept constant, i.e., cycling from group 1 to group 4, with one NEE, ER, and Rh measurement conducted within each group.

In each chamber, air temperature $(\mathrm{Ta})$ is continuously monitored $10 \mathrm{~cm}$ above the mire surface with thermocouple wires (Type K, PFA insulated, $0.25 \mathrm{~mm}$ diameter; Omega Engineering Inc., Norwalk, CT, USA). In addition, PPFD is quantified in all clear chambers using quantum sensors (Model SQ-110, Apogee Instruments Inc., Logan, UT, USA). Soil temperature (Ts) is measured at 2 and 10 $\mathrm{cm}$ depths within each chamber with thermistor probes (Model TO3R, TOJO Skogsteknik, Bygdeå, Sweden). Additional data for Ta (measured at $2 \mathrm{~m}$ height above the surface) and Ts at $2,10,18,26,34$, and $42 \mathrm{~cm}$ depths are available from a nearby $(\sim 50 \mathrm{~m})$ climate station ${ }^{30}$. Water table level (WTL) is continuously monitored at each chamber group with a submersible pressure transducer (Model CS451, Campbell Scientific, Logan, UT, USA)

Data processing, flux calculation, and quality control. The data processing, flux calculation, and quality control procedures have been described in detail by Järveoja et al. ${ }^{13}$. In brief, flux rates were computed from the linear change in the headspace carbon dioxide concentration over time (after discarding the first $20 \mathrm{~s}$ following chamber closure) corrected for air density using the ideal gas law. Hourly means of ER, $\mathrm{Ra}$, and $\mathrm{Rh}$ were calculated from the available replicate measurements within each hour (i.e., between 1 and 4). Uncertainty estimates for each hourly treatment mean flux were computed based on the $95 \%$ confidence intervals considering the number of chamber fluxes available in each hour. Hourly mean estimates of Ra were derived from the independent measurements of the ER and Rh fluxes as $\mathrm{Ra}=\mathrm{ER}-\mathrm{Rh}$. All fluxes are expressed following the atmospheric sign convention in which positive fluxes represent emission to the atmosphere.

A number of quality control procedures were applied to detect and discard poor quality flux data. Specifically, this included: (1) filtering out fluxes with an RMSE $>$ 0.5 and $R^{2}<0.95(P<0.001),(2)$ removing sporadic negative (i.e., apparent uptake) fluxes in ER and Rh, (3) eliminating Rh fluxes when the WTL was higher than $-5 \mathrm{~cm}$ from the mire surface (since the experimental plots were flooded in these conditions due to a lower surface level following the vegetation removal) and (4) filtering and correcting fluxes measured during calm nights. The last step is necessary to account for the apparent increase in nighttime flux estimates, which results from the artifact that may occur when the closing chamber disturbs the steep concentration gradient above the mire surface common for stable atmospheric conditions (see e.g., Lai et al. ${ }^{55}$; Brændholt et al. ${ }^{56}$ ). For this purpose we corrected our nighttime flux estimates with the approach developed by Järveoja et al. ${ }^{13}$. To ensure that our nighttime correction approach removed the potential bias from $\mathrm{CO}_{2}$ accumulation during calm stable nights, we created an alternative dataset in which we removed all nighttime flux data with ambient $\mathrm{CO}_{2}$ concentrations $\geq 415 \mathrm{ppm}$. A comparison of the diel patterns obtained from the original and filtered datasets suggests only negligible differences (likely resulting from the fact that the two datasets comprise different periods with varying environmental conditions) (Supplementary Fig. 13) demonstrating that our nighttime correction approach effectively eliminated the apparent bias. We further note that methane fluxes measured with the same system do not show such nighttime increase when corrected with the same approach (Supplementary Fig. 14). Altogether, this suggests that nighttime patterns in respiration fluxes observed in our final quality controlled data are due to biological processes rather than the result of a systematic artifact due to accumulation of $\mathrm{CO}_{2}$ during calm nights.

The relationships of $\mathrm{ER}, \mathrm{Rh}$, and $\mathrm{Ra}$ to temperature were estimated using the exponential model Eq. (1) by Lloyd \& Taylor ${ }^{14}$ :

$$
R=R_{10} \exp ^{E_{0}\left(\frac{1}{56.02}-\frac{1}{T-227.13}\right)},
$$

where $R$ is $\mathrm{ER}, \mathrm{Rh}$, or Ra, $T$ is temperature (i.e., $\mathrm{Ta}$ or Ts), $R_{10}$ represents base respiration at $10^{\circ} \mathrm{C}$ and $E_{0}$ represents the activation energy parameter, i.e., the sensitivity of respiration fluxes to changes in temperature.

Alternative ER estimates from a standard modeling approach. For comparing the diel ER patterns from our continuous AC measurements to those commonly obtained from extrapolation of discontinuous data, we derived an alternative ER dataset using the REddyProcWeb online tool ${ }^{26}$. This tool is the standard modeling approach within the EC flux community used to extrapolate EC-based nighttime measurements of NEE (i.e., ER) to the daytime based on exponential relationships with (air or soil) temperature ${ }^{17,26}$. To achieve this, we provided the automated chamber ER data along with key micrometeorological variables (i.e., global radiation, air temperature, relative humidity, vapor pressure deficit, and friction velocity) obtained from the nearby $(\sim 25 \mathrm{~m})$ climate station as input for the online tool algorithm which subsequently simulated diel ER. We further investigated the diel patterns of EC-based ER fluxes. For this purpose, we obtained readily available half-hourly ER estimates derived from EC measurements at the adjacent ICOSDegerö station (www.icos-sweden.se/station_degero.html) using the REddyProcWeb online tool.

Vegetation phenology. To track the seasonal vegetation biomass development with high temporal resolution, a greenness index (i.e., the green chromatic coordinate; $\mathrm{gcc}$ ) was derived from hourly images collected through digital repeat photography as described in detail by Peichl et al. ${ }^{57}$ and Järveoja et al. ${ }^{13}$. We further used gcc to determine the distinct phenophases of (1) green-up, (2) peak season, (3) senescence, and (4) dormancy (i.e., the snow-free periods before and after the growing season). Specifically, the 10 and $90 \%$ thresholds in the daily gcc between May 1 and the timing of peak gcc were used to define the transition dates from dormancy to green-up in spring and from green-up to peak season, respectively. Meanwhile, the 90 and 10\% thresholds between the timing of peak gcc and October 31 were used to define the shifts from peak season to senescence and from senescence to dormancy in autumn, respectively.

Statistical analysis. The relative importance of the various potential abiotic controls (i.e., including PPFD, WTL, Ta, and Ts at all available depths) in regulating the diel patters in $\mathrm{Rh}$ and $\mathrm{Ra}$ was examined using a wavelet coherence analysis ${ }^{58}$ of the hourly data. This analysis was complemented by determining the Welch's cross power spectral density ${ }^{59}$ for those variables that showed strong coherence and lag times of $<6 \mathrm{~h}$ with Ra or Rh. All data analysis was conducted using the Matlab software (Matlab R2019b, Mathworks, USA).

\section{Data availability}

The data sets collected and analyzed during the current study are publicly available in the Figshare digital repository at [https://doi.org/10.6084/m9.figshare.12730949.v1].

\section{Code availability}

Data processing scripts are available upon reasonable request from the corresponding author.

Received: 24 January 2020; Accepted: 29 July 2020;

Published online: 26 August 2020

\section{References}

1. Turunen, J., Tomppo, E., Tolonen, K. \& Reinikainen, A. Estimating carbon accumulation rates of undrained mires in Finland-application to boreal and subarctic regions. Holocene 12, 69-80 (2002). 
2. Gorham, E. Northern Peatlands: role in the carbon cycle and probable responses to climatic warming. Ecol. Appl. 1, 182-195 (1991).

3. Loisel, J. et al. A database and synthesis of northern peatland soil properties and Holocene carbon and nitrogen accumulation. Holocene 24, 1028-1042 (2014).

4. Yu, Z., Loisel, J., Brosseau, D. P., Beilman, D. W. \& Hunt, S. J. Global peatland dynamics since the Last Glacial Maximum. Geophys. Res. Lett. 37, L13402 (2010).

5. Batjes, N. H. Total carbon and nitrogen in the soils of the world. Eur. J. Soil Sci. 65, 10-21 (2014).

6. Dorrepaal, E. et al. Carbon respiration from subsurface peat accelerated by climate warming in the subarctic. Nature 460, 616-619 (2009).

7. Nijp, J. J. et al. Rain events decrease boreal peatland net $\mathrm{CO}_{2}$ uptake through reduced light availability. Glob. Change Biol. 21, 2309-2320 (2015).

8. Petrescu, A. M. R. et al. The uncertain climate footprint of wetlands under human pressure. Proc. Natl Acad. Sci. USA. 112, 4594-4599 (2015).

9. Wu, J. \& Roulet, N. T. Climate change reduces the capacity of northern peatlands to absorb the atmospheric carbon dioxide: the different responses of bogs and fens. Glob. Biogeochem. Cycles 28, 1005-1024 (2014).

10. Wang, X. et al. Soil respiration under climate warming: differential response of heterotrophic and autotrophic respiration. Glob. Change Biol. 20, 3229-3237 (2014).

11. Mäkiranta, P. et al. Indirect regulation of heterotrophic peat soil respiration by water level via microbial community structure and temperature sensitivity. Soil Biol. Biochem. 41, 695-703 (2009).

12. Bond-Lamberty, B., Wang, C. \& Gower, S. T. A global relationship between the heterotrophic and autotrophic components of soil respiration? Glob. Change Biol. 10, 1756-1766 (2004).

13. Järveoja, J., Nilsson, M. B., Gažovič, M., Crill, P. M. \& Peichl, M. Partitioning of the net $\mathrm{CO}_{2}$ exchange using an automated chamber system reveals plant phenology as key control of production and respiration fluxes in a boreal peatland. Glob. Change Biol. 24, 3436-3451 (2018).

14. Lloyd, J. \& Taylor, J. A. On the temperature dependence of soil respiration Funct. Ecol. 8, 315 (1994).

15. van't Hoff, J. H. Lectures on theoretical and physical chemistry: chemical dynamics. Part I (Edward Arnold, London, 1898).

16. Arrhenius, S. Uber die Reaktionsgeschwindigkeit bei der Inversion von Rohrzucker durch Sauren. Z. f.ür. Phys. Chem. 4, 226-248 (1889).

17. Reichstein, M. et al. On the separation of net ecosystem exchange into assimilation and ecosystem respiration: review and improved algorithm. Glob. Change Biol. 11, 1424-1439 (2005).

18. Lasslop, G. et al. Separation of net ecosystem exchange into assimilation and respiration using a light response curve approach: critical issues and global evaluation. Glob. Change Biol. 16, 187-208 (2010).

19. Lasslop, G. et al. On the choice of the driving temperature for eddy-covariance carbon dioxide flux partitioning. Biogeosciences 9, 5243-5259 (2012).

20. Wohlfahrt, G. \& Galvagno, M. Revisiting the choice of the driving temperature for eddy covariance $\mathrm{CO}_{2}$ flux partitioning. Agric. Meteorol. 237-238, 135-142 (2017).

21. Phillips, S. C. et al. Interannual, seasonal, and diel variation in soil respiration relative to ecosystem respiration at a wetland to upland slope at Harvard Forest. J. Geophys. Res. Biogeosciences 115, G02019 (2010).

22. Savage, K., Davidson, E. A. \& Tang, J. Diel patterns of autotrophic and heterotrophic respiration among phenological stages. Glob. Change Biol. 19, 1151-1159 (2013).

23. Thorne, R., Khomik, M., Hayman, E. \& Arain, A. Response of soil $\mathrm{CO}_{2}$ efflux to shelterwood harvesting in a mature temperate pine forest. Forests 11, 304 (2020).

24. Carbone, M. S., Winston, G. C. \& Trumbore, S. E. Soil respiration in perennial grass and shrub ecosystems: linking environmental controls with plant and microbial sources on seasonal and diel timescales. J. Geophys. Res. Biogeosciences 113, G02022 (2008).

25. Keane, J. Ben \& Ineson, P. Technical note: differences in the diurnal pattern of soil respiration under adjacent Miscanthus $\times$ giganteus and barley crops reveal potential flaws in accepted sampling strategies. Biogeosciences 14, 1181-1187 (2017).

26. Wutzler, T. et al. Basic and extensible post-processing of eddy covariance flux data with REddyProc. Biogeosciences 15, 5015-5030 (2018).

27. Luo, Y. \& Zhou, X. Soil respiration and the environment. (Academic Press, An Imprint of Elsevier Science, London, 2006).

28. Hoffmann, M. et al. Automated modeling of ecosystem $\mathrm{CO}_{2}$ fluxes based on periodic closed chamber measurements: a standardized conceptual and practical approach. Agric. Meteorol. 200, 30-45 (2015).

29. Rochette, P. \& Hutchinson, G. Measurement of soil respiration in situ: chamber techniques. in Micrometeorology in agricultural systems, Agron. Monogr. 47 (ASA, CSSA and SSSA, Madison, WI 2005).

30. Peichl, M. et al. A 12-year record reveals pre-growing season temperature and water table level threshold effects on the net carbon dioxide exchange in a boreal fen. Environ. Res. Lett. 9, 055006 (2014).
31. Nilsson, M. et al. Contemporary carbon accumulation in a boreal oligotrophic minerogenic mire - a significant sink after accounting for all C-fluxes. Glob. Change Biol. 14, 2317-2332 (2008).

32. Qiu, C. et al. ORCHIDEE-PEAT (revision 4596), a model for northern peatland $\mathrm{CO}$, water, and energy fluxes on daily to annual scales. Geosci. Model Dev. 11, 497-519 (2018).

33. Abdalla, M. et al. Simulation of $\mathrm{CO} 2$ and attribution analysis at Six European Peatland sites using the ECOSSE model. Water, Air, Soil Pollut. 225, 2182 (2014).

34. Metzger, C., Nilsson, M. B., Peichl, M. \& Jansson, P.-E. Parameter interactions and sensitivity analysis for modelling carbon heat and water fluxes in a natural peatland, using CoupModel v5. Geosci. Model Dev. 9, 4313-4338 (2016).

35. Jung, M. et al. Global patterns of land-atmosphere fluxes of carbon dioxide, latent heat, and sensible heat derived from eddy covariance, satellite, and meteorological observations. J. Geophys. Res. 116, G00J07 (2011).

36. Ai, J. et al. MODIS-based estimates of global terrestrial ecosystem respiration. J. Geophys. Res. Biogeosciences 123, 326-352 (2018).

37. Xiao, J. et al. Remote sensing of the terrestrial carbon cycle: a review of advances over 50 years. Remote Sens. Environ. 233, 111383 (2019).

38. Badawy, B., Arora, V. K., Melton, J. R. \& Nassar, R. Modeling the diurnal variability of respiratory fluxes in the Canadian Terrestrial Ecosystem Model (CTEM). J. Adv. Model. Earth Syst. 8, 614-633 (2016).

39. Wu, Y., Verseghy, D. L. \& Melton, J. R. Integrating peatlands into the coupled Canadian Land Surface Scheme (CLASS) v3.6 and the Canadian Terrestrial Ecosystem Model (CTEM) v2.0. Geosci. Model Dev. 9, 2639-2663 (2016).

40. Waddington, J. M., Rotenberg, P. A. \& Warren, F. J. Peat $\mathrm{CO}_{2}$ production in a natural and cutover peatland: implications for restoration. Biogeochemistry $\mathbf{5 4}$, $115-130$ (2001)

41. Glatzel, S., Basiliko, N. \& Moore, T. Carbon dioxide and methane production potentials of peats from natural, harvested and restored sites, eastern Québec, Canada. Wetlands 24, 261-267 (2004).

42. Hoyos-Santillan, J. et al. Quality not quantity: organic matter composition controls of $\mathrm{CO} 2$ and $\mathrm{CH} 4$ fluxes in neotropical peat profiles. Soil Biol. Biochem. 103, 86-96 (2016).

43. Moore, T. R. \& Dalva, M. Methane and carbon dioxide exchange potentials of peat soils in aerobic and anaerobic laboratory incubations. Soil Biol. Biochem. 29, 1157-1164 (1997).

44. Nilsson, M. \& Öquist, M. Partitioning litter mass loss into carbon dioxide and methane in peatland ecosystems. in Carbon Cycling in Northern Peatlands (American Geophysical Union, Washington, DC, 2009).

45. Blodau, C., Basiliko, N. \& Moore, T. R. Carbon turnover in peatland mesocosms exposed to different water table levels. Biogeochemistry 67 , 331-351 (2004)

46. D'Angelo, B. et al. Soil temperature synchronisation improves representation of diel variability of ecosystem respiration in Sphagnum peatlands. Agric. Meteorol. 223, 95-102 (2016).

47. Phillips, C. L., Nickerson, N., Risk, D. \& Bond, B. J. Interpreting diel hysteresis between soil respiration and temperature. Glob. Change Biol. 17, 515-527 (2011).

48. Chapin, F. S. III, Matson, P. A. \& Mooney, H. A. Carbon input to terrestrial ecosystems. in principles of terrestrial ecosystem. Ecology. (Springer, New York, NY, 2002).

49. Vargas, R. \& Allen, M. F. Environmental controls and the influence of vegetation type, fine roots and rhizomorphs on diel and seasonal variation in soil respiration. N. Phytol. 179, 460-471 (2008).

50. Bahn, M., Schmitt, M., Siegwolf, R., Richter, A. \& Brüggemann, N. Does photosynthesis affect grassland soil-respired $\mathrm{CO}_{2}$ and its carbon isotope composition on a diurnal timescale? N. Phytol. 182, 451-460 (2009).

51. Laine, A. M. et al. Abundance and composition of plant biomass as potential controls for mire net ecosytem CO2 exchange. Botany 90, 63-74 (2012).

52. Goulden, M. L. \& Crill, P. M. Automated measurements of $\mathrm{CO} 2$ exchange at the moss surface of a black spruce forest. Tree Physiol. 17, 537-542 (1997).

53. Bubier, J., Crill, P., Mosedale, A., Frolking, S. \& Linder, E. Peatland responses to varying interannual moisture conditions as measured by automatic $\mathrm{CO} 2$ chambers. Glob. Biogeochem. Cycles 17, 1066 (2003).

54. Bond-Lamberty, B., Bronson, D., Bladyka, E. \& Gower, S. T. A comparison of trenched plot techniques for partitioning soil respiration. Soil Biol. Biochem. 43, 2108-2114 (2011).

55. Lai, D. Y. F., Roulet, N. T., Humphreys, E. R., Moore, T. R. \& Dalva, M. The effect of atmospheric turbulence and chamber deployment period on autochamber $\mathrm{CO}_{2}$ and $\mathrm{CH}_{4}$ flux measurements in an ombrotrophic peatland. Biogeosciences 9, 3305-3322 (2012).

56. Brændholt, A., Larsen, K. S., Ibrom, A. \& Pilegaard, K. Overestimation of closed-chamber soil $\mathrm{CO} 2$ effluxes at low atmospheric turbulence. Biogeosciences 14, 1603-1616 (2017).

57. Peichl, M., Sonnentag, O. \& Nilsson, M. B. Bringing color into the picture: using digital repeat photography to investigate phenology controls of the carbon dioxide exchange in a boreal mire. Ecosystems 18, 115-131 (2015). 
58. Grinsted, A., Moore, J. C. \& Jevrejeva, S. Application of the cross wavelet transform and wavelet coherence to geophysical time series. Nonlinear Process. Geophys. 11, 561-566 (2004).

59. Welch, P. The use of fast Fourier transform for the estimation of power spectra: a method based on time averaging over short, modified periodograms. IEEE Trans. Audio Electroacoust. 15, 70-73 (1967)

\section{Acknowledgements}

J.J. acknowledges a Postdoctoral Scholarship from the Carl Tryggers Foundation (CTS 15-377) and funding from the Swedish Forest Society Foundation (2018-485-Steg 2 2017). The automated chamber system was financed by a grant from the Carl Kempe Foundation (JCK-1108). Financial support from the Swedish Research Council and contributing research institutes to both the Swedish Infrastructure for Ecosystem Science (SITES) and the Swedish Integrated Carbon Observation System (ICOS-Sweden) Research Infrastructure are acknowledged. We are grateful to Natxo Garcia Lopez and Draupnir Einarsson for building the automated chamber system and appreciate the additional contributions from Anders Lindström and the late Lars Lundmark. We also thank Eric Larmanou and Pernilla Löfvenius from the Svartberget field research station for help in maintaining the automated chamber system and phenocam image archive, respectively.

\section{Author contributions}

J.J., M.P., and M.B.N. designed the study. P.M.C. developed the automated chamber system. J.J. collected and processed the data, performed the analysis, and wrote the paper. M.P. contributed to the writing of the paper. All authors participated in interpreting the results and provided feedback on the paper.

\section{Competing interests}

The authors declare no competing interests.

\section{Additional information}

Supplementary information is available for this paper at https://doi.org/10.1038/s41467020-18027-1.

Correspondence and requests for materials should be addressed to J.J.

Peer review information Nature Communications thanks Markku Koskinen and other, anonymous, reviewers for their contributions to the peer review of this work. Peer review reports are available.

Reprints and permission information is available at http://www.nature.com/reprints

Publisher's note Springer Nature remains neutral with regard to jurisdictional claims in published maps and institutional affiliations.

\begin{abstract}
(c) (i) Open Access This article is licensed under a Creative Commons Attribution 4.0 International License, which permits use, sharing, adaptation, distribution and reproduction in any medium or format, as long as you give appropriate credit to the original author(s) and the source, provide a link to the Creative Commons license, and indicate if changes were made. The images or other third party material in this article are included in the article's Creative Commons license, unless indicated otherwise in a credit line to the material. If material is not included in the article's Creative Commons license and your intended use is not permitted by statutory regulation or exceeds the permitted use, you will need to obtain permission directly from the copyright holder. To view a copy of this license, visit http://creativecommons.org/ licenses/by/4.0/.
\end{abstract}

(C) The Author(s) 2020 